\title{
Cure Characteristics and Physicomechanical Properties of Calcium Carbonate Reinforcement Rubber Composites
}

\author{
Maged S. Sobhy ${ }^{1 *}$, D. E. El-Nashar ${ }^{2}$, and Nabila A. Maziad ${ }^{3}$ \\ ${ }^{1}$ Materials Sci. Lab., Phys. Dept., Faculty of Sci., Cairo University at \\ Beni-Suef, Egypt. \\ ${ }^{2}$ Polymers and Pigments, National Research Center (NRC), \\ Dokki, Cairo, Egypt. \\ ${ }^{3}$ Department of Polymer Chemistry, National Center for Radiation Research \\ and Technology (NCRRT), Nasr City, Cairo, Egypt.
}

\begin{abstract}
Cure characteristics and physicomechanical properties of calcium carbonate, $\mathrm{CaCO}_{3}$, reinforced rubbers (NR, NBR) were studied. Minimum torque, maximumminimum torque, cure rate and the scorch and cure time of the prepared rubber compounds were assessed by using a Monsanto Oscillating Disc Rheometer (ODR100). Stress and strain at yield and at rupture before and after aging were determined by using a Zwick tensile testing machine (Model 1425). Results showed that cure time, cure rate index (CRI), maximum torque, stress and strain at yield demonstrated clearly the optimum filler content for each type of rubber. Values of the rubber-filler interaction parameter $(m)$ were 0.585 and 0.175 for NR and NBR respectively and suggested good NR-filler interaction than that of NBR where the dilution effect of NBR becomes more significant as the filler loading is increased. The aging behavior (resistance to deterioration) of the prepared rubber compounds due to the prolonged exposure of $\gamma$-irradiation was estimated by plotting the percent-retained values of the physicomechanical properties at different $\gamma$-doses.
\end{abstract}

\section{Introduction:}

One of the most important phenomena in material science is the reinforcement of rubber by rigid entities, such as carbon black, clays, silicates, and calcium carbonate [1-3]. Thus, these fillers, or reinforcement aids are added to rubber formulations to optimize properties that meet a given service application or sets of performance parameters [4-9]. Although the original purpose is to lower the cost of the molding compounds, prime importance is now attached to the selective active fillers and its quantity that produce specific improvements in rubber physical properties.

\footnotetext{
* Correspondence to M.S.Sobhy (MS_Sobhy@yahoo.com)
} 
$\mathrm{CaCO}_{3}$ particles are generally supplied as agglomerates and during processing they are broken and dispersed into primary particles. Large particleparticle interactions result in inhomogeneous distribution of the filler, processing problems, poor appearance, and inferior properties. This fact may emphasize the importance of homogeneity where the increasing amount of aggregates leads to a decrease of tensile properties of the rubber composites [10-12]. It is well known that the overall performance of composites is achieved by the addition of a low molecular weight organic compound, such as stearic acid [13], resulting in a better dispersion of the particles in the rubber matrix. Finally, aging behavior is taken here as deterioration due to the prolonged action of high-energy radiation [2], where several changes in the chemical network structure can occur. Evaluation of aging behavior isn't only estimated from the changes in tensile properties but also to include liquid absorption measurements.

This article deals with the effect of $\mathrm{CaCO}_{3}$ addition to natural rubber (NR) or nitrile rubber (NBR) on the cure characteristics and physicomechanical properties. It is also aimed to study the aging performance due to the prolonged action of different $\gamma$-irradiation doses up to $50 \mathrm{Mrad}$.

\section{Experimental}

\subsection{Materials}

- Natural rubber (NR): ribbed smoked sheets SMR-20 with specific gravity $0.913 \pm 0.005 \mathrm{~g} / \mathrm{cm}^{3}$, and low $\mathrm{T}_{\mathrm{g}}=-75{ }^{\circ} \mathrm{C}$, supplied by Transport and Engineering Company, Alexandria, Egypt.

- Nitrile rubber (NBR), 32\% acrylonitrile content and 0.5\% ash, specific gravity $1.17 \pm 0.005 \mathrm{~g} / \mathrm{cm}^{3}$, Bayer AG (Germany).

- N-cyclohexyl-2-benzothiazyl sulfonamide (CBS), and phenyl- $\beta$ naphthylamine $(\mathrm{P} \beta \mathrm{N})$ were the used accelerator and antioxidant respectively.

- Calcium carbonate was chosen as a filler throughout this article, and its technical specifications are given in Table (1).

- Other standard rubber compounding ingredients such as stearic acid, zinc oxide and sulfur were of commercial grades and used without further purification.

- Toluene used for swelling had a density of $0.86 \mathrm{~g} / \mathrm{ml}$ and boiling point 109 $112^{\circ} \mathrm{C}$.

Table (1) : Technical Specifications of Calcium Carbonate $\left(\mathrm{CaCO}_{3}\right)$ Property 


\begin{tabular}{|c|c|}
\hline Specific gravity $\left(\mathrm{g} / \mathrm{cm}^{3}\right)$ & 2.65 \\
Oil absorption & 35 \\
Particle size $(\mu \mathrm{m})$ & 3.25 \\
Surface area $\left(\mathrm{m}^{2} / \mathrm{g}\right)$ & 3.6 \\
\hline
\end{tabular}

\subsection{Compounding}

A typical formulation of rubber compound is shown in Table (2). Using a two-roll mill that is maintained at nearly $50{ }^{\circ} \mathrm{C}$, as described by the American Society for Testing and Materials ASTM D3184-89 performed the compounding procedure. Rubber mixes were conditioned at nearly $25{ }^{\circ} \mathrm{C}$ for 24 $\mathrm{h}$ prior to cure assessment on a Monsanto Oscillating Disc Rheometer-100, according to ASTM D1646.

The vulcanization was carried out in a hydraulic press under a pressure of about $4 \mathrm{MPa}, 142{ }^{\circ} \mathrm{C}$ and $162{ }^{\circ} \mathrm{C}$ for NR and NBR compounds respectively, for the optimum cure time obtained from rheometer data.

Table (2) : A Typical Formulation of Rubber Compounds

\begin{tabular}{|c|c|}
\hline Ingredient & Recipe, $\mathrm{phr}^{\mathrm{a}}$ \\
\hline Rubber $^{b}$ & 100 \\
\hline Stearic acid & 2 \\
\hline Zinc oxide & 4 \\
\hline Filler $^{c}$ & Variable \\
\hline Oil & 3 \\
\hline $\mathrm{P} \beta \mathrm{N}$ & 1 \\
\hline CBS & 1 \\
\hline Sulfur & 2 \\
\hline
\end{tabular}

${ }^{a}$ parts per hundred parts of rubber

${ }^{b}$ NR or NBR

${ }^{\mathrm{c}}$ Calcium Carbonate (Loading from $0-60 \mathrm{phr}$ )

\subsection{Measurements}

\subsubsection{The tensile experiment:}

Tensile tests were performed on the dumbbell samples that were cut from a $2 \mathrm{~mm}$ thick molded rubber sheet. The tensile strength, $\sigma_{\mathrm{y}}$, and ultimate elongation, $E_{b} \%$, were determined at room temperature of the rubber samples using a Zwick 1425 tensile testing machine according to ASTM D412-98a.

\subsubsection{Swelling measurements:}


Swelling test (ASTM D471) were performed on a uniform circular cut from the compression-molded rubber samples with $5 \mathrm{~mm}$ diameter and $2 \mathrm{~mm}$ thick by the immersion/gain method [14] in pure toluene at room temperature for two days to allow the swelling to reach diffusion equilibrium. Then, the test piece was taken out and rapidly removed by blotting liquid with filter paper. The swelling ratio is defined as:

$$
\mathrm{R}=\frac{\mathrm{W}_{\mathrm{t}}-\mathrm{W}_{0}}{\mathrm{~W}_{0}}
$$

where $\mathrm{W}_{0}$ and $\mathrm{W}_{\mathrm{t}}$ are the weights of the test piece before swelling and after time ' $t$ ' of immersion respectively. The swelling ratio is a direct measurement of the degree of crosslinking. The volume fraction of rubber, $\Phi_{\mathrm{r}}$, in the swollen network was then calculated $[15,16]$ using the following equation:

$$
1 / \Phi_{\mathrm{r}}=1+\left(\mathrm{W}_{\mathrm{s}} \rho_{\mathrm{r}} / \mathrm{W}_{\mathrm{r}} \rho_{\mathrm{s}}\right)
$$

where $\mathrm{W}_{\mathrm{r}}$ and $\mathrm{W}_{\mathrm{s}}$ are weights of the specimen, dried and swollen respectively. $\rho_{\mathrm{r}}$ and $\rho_{\mathrm{s}}$ are the density of the rubber compound and solvent respectively. The crosslink density was determined using the Flory-Rehner equation $[17,18]$.

$$
\left.\mathrm{M}_{\mathrm{c}}=\frac{-\rho_{\mathrm{r}} V_{\mathrm{S}}\left(\Phi_{r}^{1 / 3}-\Phi_{r}^{1 / 2}\right)}{\ln \left(1-\Phi_{\mathrm{r}}\right)+\Phi_{\mathrm{r}}+\chi \Phi_{\mathrm{r}}^{2}}\right]
$$

where $\mathrm{V}_{\mathrm{s}}$ is the molar volume of the solvent and $\chi$ the Huggins polymer-solvent interaction parameter, which is given by the equation proposed by Hildebrand [19].

$$
\chi=\frac{\mathrm{V}_{\mathrm{s}}\left(\delta_{s}-\delta_{\mathrm{r}}\right)^{2}}{\mathrm{RT}}+\beta
$$

where $\beta$ is the lattice constant which was taken as $0.38, \delta_{\mathrm{s}}$ and $\delta_{\mathrm{r}}$ are the solubility parameter of the solvent and rubber respectively, $\mathrm{R}$ is the universal gas constant, and $\mathrm{T}$ the absolute temperature.

\subsubsection{Scanning Electron Microscope (SEM):}

SEM images of morphology were done on a Joel JSM-5400 for the dispersion observations.

\subsubsection{Aging Behavior:}


For the study of aging performance, deterioration by $\gamma$-irradiation of the prepared samples were carried out at room temperature in the "National Center for Research and Radiation Technology" (NCRRT), Atomic Energy Authority, Nasr City, Cairo, Egypt. A gamma chamber of ${ }^{60} \mathrm{Co}$ source was used to give a dose rate of nearly $1.25 \times 10^{6} \mathrm{rad} / \mathrm{hr}$.

\section{Results and Discussion}

\subsection{Cure Characteristics}

The cure characteristics of $\mathrm{CaCO}_{3}$ loaded the rubber matrix (NR or NBR) is shown in Table (3). The results seemed to be dependent mainly on the rubber matrix. Values of the cure time, $t_{90}$, are decreased with increasing $\mathrm{CaCO}_{3}$ content for both rubber compounds. The NBR matrix exhibits longer $\mathrm{T}_{\mathrm{C} 90}$ than those of NR compounds. This result can be related to the fact that $\mathrm{CaCO}_{3}$ particles are isotropic in nature, have small nucleation effect $[12,20]$ and interact strongly with rubber especially with a polar rubber such as NBR [10]. Cure rate index (CRI), which is a measure of the rate of the cure reaction [21], is given by:

$$
\text { CRI }=\frac{100}{T_{C 90}-T_{S 2}}
$$

It is seen that $\mathrm{CRI}$ increases with $\mathrm{CaCO}_{3}$ addition and it supports the activation of the cure reaction up to $20 \mathrm{phr}$ and $40 \mathrm{phr}$ for NR and NBR respectively. At higher loading, a deactivation of the cure process was observed due to the increase of the optimum cure time, $\mathrm{t}_{\mathrm{C} 90}$ values, resulting in a poor interfacial interaction between rubber and $\mathrm{CaCO}_{3}$, which confirmed the tendency of the filled compounds to form filler agglomerates. Therefore, to evaluate the activity of $\mathrm{CaCO}_{3}$ for reinforcement potential, the following expression was employed:

$$
\alpha=\frac{\mathrm{D}_{\text {max }}-\mathrm{D}_{\text {max }}^{\circ}}{\mathrm{D}_{\text {max }}^{\circ}}
$$

where $\mathrm{D}_{\max }$ and $\mathrm{D}_{\max }^{\circ}$ are the maximum torque of filled matrix and gum vulcanizates, and $\alpha$ is the relative increase of the maximum torque that should increase when $\mathrm{CaCO}_{3}$ is incorporated into a rubber matrix in rheometer torque data during vulcanization as shown in Table (3).

Table (3) : Vulcanization Parameters 


\begin{tabular}{|c|c|c|c|c|c|c|c|}
\hline \multirow{2}{*}{ Matrix } & $\begin{array}{c}\text { Filler, } \\
\text { phr }\end{array}$ & \multicolumn{2}{|c|}{ Torque, $\mathrm{dNm}$} & \multirow{2}{*}{$\alpha \times 10^{-2}$} & $\begin{array}{c}\left(\mathrm{T}_{\mathrm{S} 2}\right)^{\mathrm{a}}, \\
\mathrm{min}\end{array}$ & $\begin{array}{c}\left(\mathrm{T}_{\mathrm{C} 90}\right)^{\mathrm{b}}, \\
\mathrm{min}\end{array}$ & $\begin{array}{c}\mathrm{CRI}^{\mathrm{c}} \\
\mathrm{min}^{-1}\end{array}$ \\
\hline \multirow{5}{*}{ NR } & 0 & 5 & 46 & --- & 2 & 14 & 8.33 \\
& 10 & 3.5 & 49 & 6.52 & 3 & 13 & 10.0 \\
& 20 & 3 & 52 & 13.04 & 3 & 12 & 11.11 \\
& 40 & 2 & 50 & 8.70 & 2.5 & 13 & 9.53 \\
& 60 & 2.5 & 48 & 4.35 & 2.5 & 14 & 8.70 \\
\hline \multirow{6}{*}{ NBR } & 0 & 5 & 76 & --- & 8 & 23 & 6.67 \\
& 10 & 8 & 82 & 7.89 & 8 & 20 & 8.33 \\
& 20 & 9 & 84 & 10.53 & 7 & 19 & 8.33 \\
& 40 & 8 & 88 & 15.79 & 6 & 17 & 9.09 \\
& 60 & 8 & 86 & 13.16 & 6 & 20 & 7.14 \\
\hline
\end{tabular}

${ }^{\text {a }}$ Scorch time.

${ }^{\mathrm{b}}$ Cure time.

${ }^{\mathrm{c}}$ Cure Rate Index $\left[=100 /\left(\mathrm{t}_{\mathrm{C} 90}-\mathrm{t}_{\mathrm{S} 2}\right)\right]$.

In Fig. (1a), the linear relationship between $\Delta$ torque, $\left(\mathrm{D}_{\max }-\mathrm{D}_{\min }\right)$, and $\mathrm{CaCO}_{3}$ loading exhibits higher values for NBR matrix than those obtained for NR, which result in the formation of filler agglomeration especially at higher loading. The ratio between the torque increase of the filled compound and that of the gum was found to be directly proportional to filler loading as shown in Figure (1b).

$$
\frac{\mathrm{D}_{\max }-\mathrm{D}_{\min }}{\mathrm{D}_{\max }^{\circ}-\mathrm{D}_{\min }^{\circ}}-1=\alpha_{\mathrm{f}} \frac{\mathrm{m}_{\mathrm{f}}}{\mathrm{m}_{\mathrm{r}}}
$$

where $\mathrm{D}_{\text {max }}-\mathrm{D}_{\text {min }}$ is the maximum change in torque during vulcanization for filled rubber, $D_{\max }^{\circ}-D_{\min }^{\circ}$ is the maximum change in torque during vulcanization for gum, $\mathrm{m}_{\mathrm{r}}$ is the mass of rubber in the compound, $\mathrm{m}_{\mathrm{f}}$ is the mass of filler in the compound, and $\alpha_{\mathrm{f}}$ is a filler specific constant that is independent of the cure system and closely related to the morphology of the filler [6,7]. The relative torque shows an increasing value as a function of the continuous incorporation of $\mathrm{CaCO}_{3}$ up to $20 \mathrm{phr}$ and $40 \mathrm{phr}$ for NR and NBR respectively. These compositions could be considered as the optimum concentrations, i.e. a good dispersion of filler up to the estimated optimum values for NR and NBR compounds are achieved, resulting in better interfacial interaction between rubber and filler. 

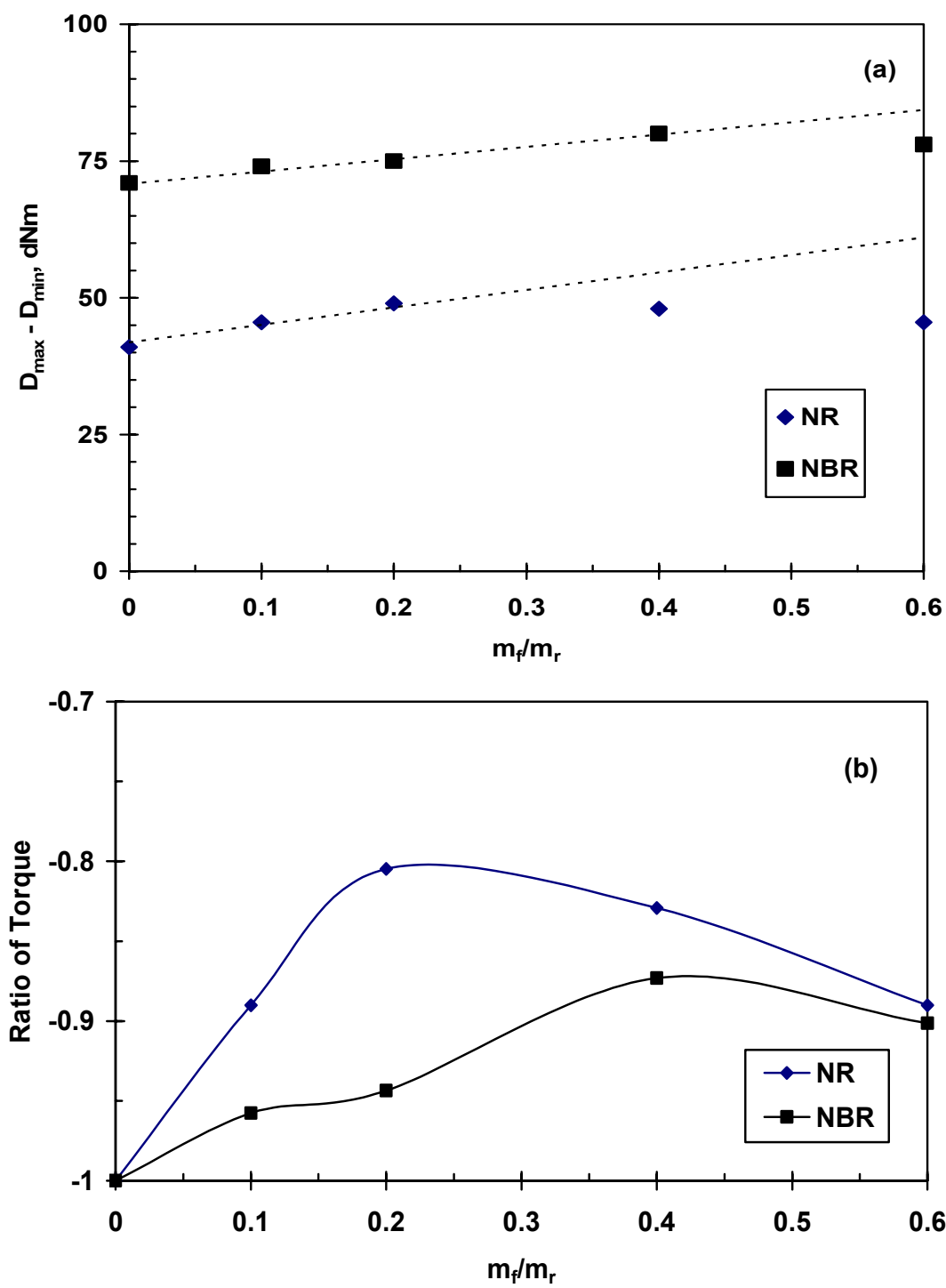

Fig. (1): Variation of (a) $\Delta$ Torque $\left(D_{\max }-D_{\min }\right)$; eqn. 6 , and (b) Ratio of Torque; eqn. 7 , as a function of $\mathrm{CaCO}_{3}$ loading at different rubber compounds.

\subsection{Swelling Properties}

The influence of $\mathrm{CaCO}_{3}$ addition to the swelling ratio values of the proposed rubber specimens in toluene is plotted against square root of time $\left(\mathrm{t}^{1 / 2}\right)$ at room temperature as shown in Figure $(2 \mathrm{a}, \mathrm{b})$. Initially, swelling curves exhibit a linear portion followed by a plateau region at longer time. Again, the results seemed to be nearly dependent on the rubber matrix due to the filler- 
matrix effects during vulcanization where NBR matrix shows lower values than NR. Fig. (3) shows the variation of the maximum values of swelling ratios as a function of the $\mathrm{CaCO}_{3}$ content; these values give a direct measure of the crosslinking density, $v_{e}$, where as the swelling ratio decreases the degree of crosslinking increases. The rubber-filler interaction values are estimated from the data of the swelling experiment and according to Kraus equation $[6,7,21]$ :

$$
\frac{\Phi_{o}}{\Phi_{r}}=1-\frac{m C}{1-C}
$$

where $\Phi_{\mathrm{r}}$ and $\Phi_{\mathrm{o}}$ are the volume fractions of the filled rubber and pure gum vulcanizates respectively, and $\mathrm{m}$ is the rubber-filler interaction parameter that is easily obtained from the slope. The obtained $\mathrm{m}$-values were 0.585 and 0.175 for NR and NBR respectively and suggested NR-filler interaction which is better than that of NBR. In both rubbers, values of $\Phi_{\mathrm{o}} / \Phi_{\mathrm{r}}$ decrease with increasing filler loading above the estimated optimum values due to their agglomeration.

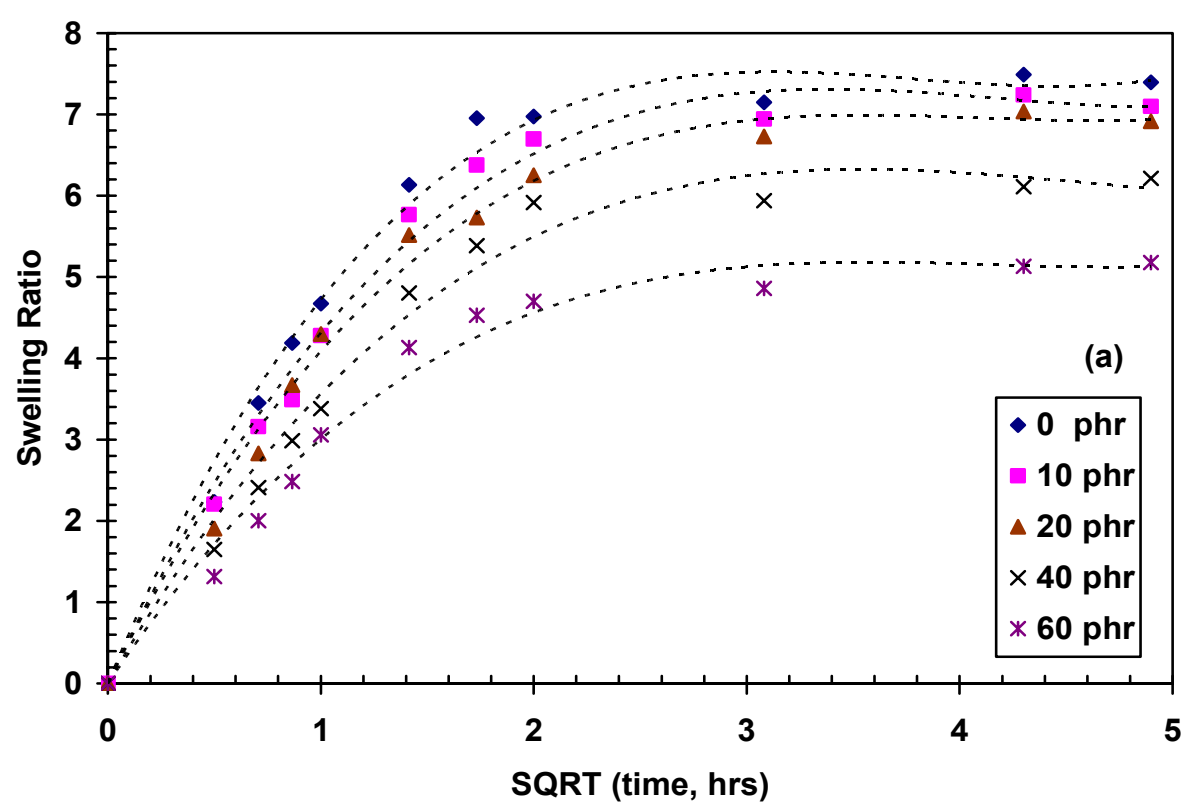




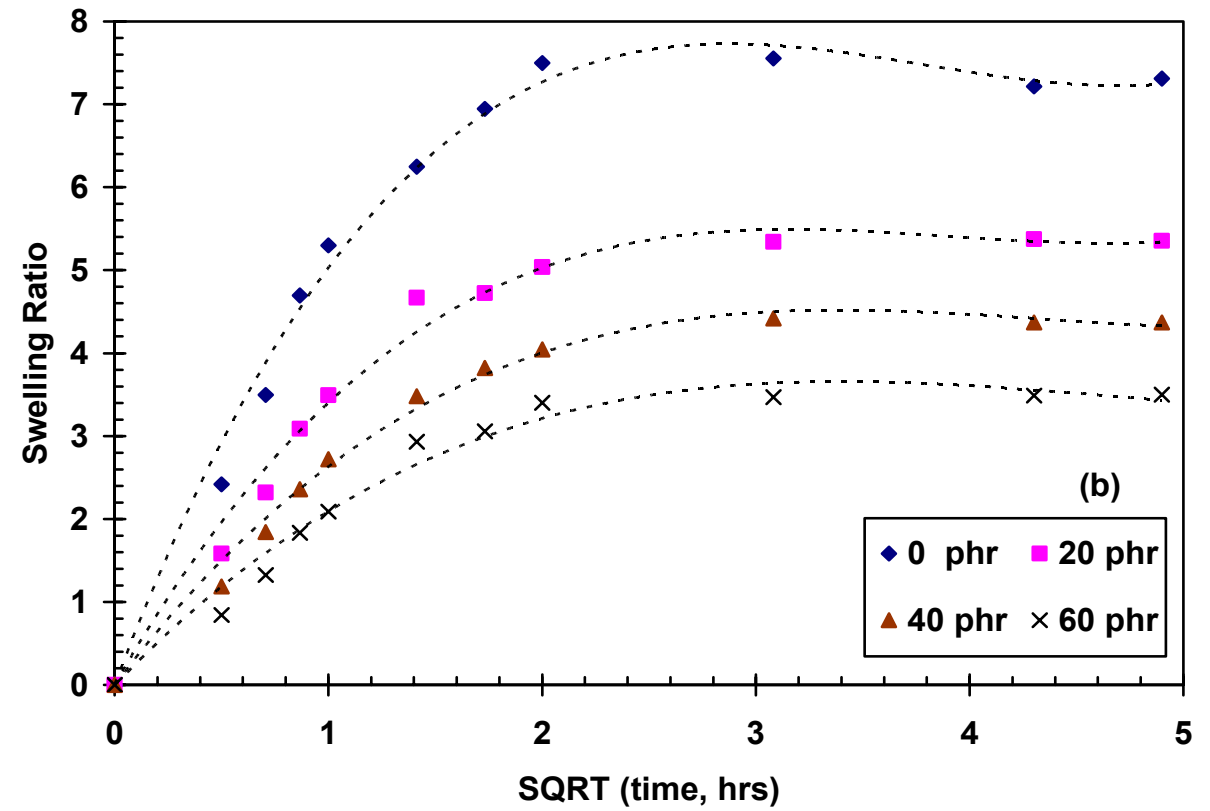

Fig. (2): Swelling ratio of $\mathrm{CaCO}_{3}$ filled (a) NR and (b) NBR.

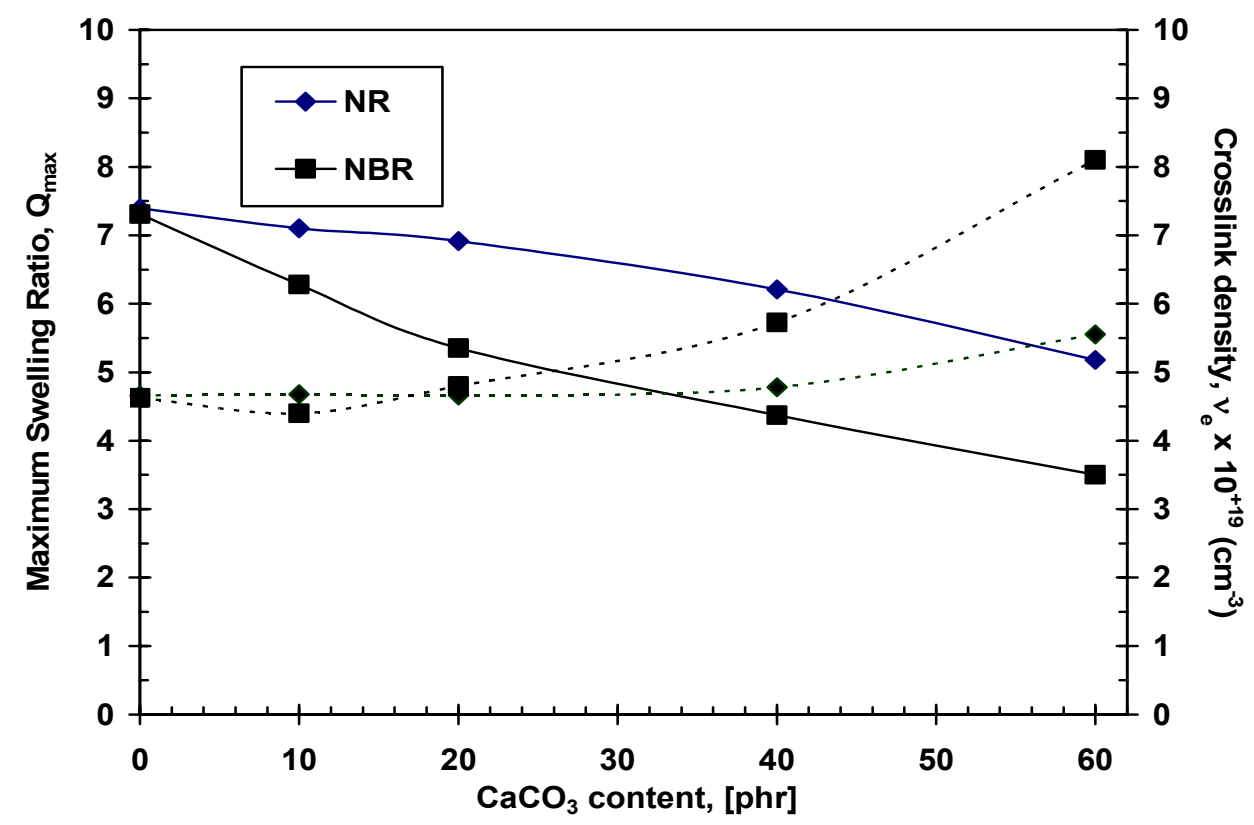

Fig. (3): Variation of both the maximum swelling ratio, $Q_{\max }$, and the crosslinking density, $v_{\mathrm{e}}$, as a function of the $\mathrm{CaCO}_{3}$ content of the rubber compounds. 


\subsection{Mechanical Properties}

\subsubsection{Tensile Strength}

The effect of $\mathrm{CaCO}_{3}$ addition on tensile strength for NR or NBR compounds is presented in Table (4). As a general feature, the tensile strength values are mainly dependent on the host matrix and a more significant increase at $20 \mathrm{phr}$ and $40 \mathrm{phr}$ are exhibited for NR and NBR respectively. Unfortunately, a more significant reinforcing effect is expected with the optimum concentrations of $\mathrm{CaCO}_{3}$ for each rubber compounds separately. While at higher filler content, the tensile strength is decreased, resulting in a poor dispersion of the filler on the rubber matrix. This behavior can be related to the probable tendency to form filler agglomerates.

Table (4) : Mechanical properties of $\mathrm{CaCO}_{3}$ filler rubber vulcanizates

\begin{tabular}{|c|c|c|c|c|c|}
\hline \multirow{2}{*}{ Matrix } & \multicolumn{2}{|c|}{ Filler } & \multirow{2}{*}{$\begin{array}{l}{\left[\mathrm{T}_{\mathrm{b}}\right]^{\mathrm{a}},} \\
\mathrm{MPa}\end{array}$} & \multirow{2}{*}{$\begin{array}{l}\text { Reinforcement } \\
\text { Index }\end{array}$} & \multirow{2}{*}{$E_{b}, \%$} \\
\hline & $\%$ & $\mathrm{phr}$ & & & \\
\hline \multirow{5}{*}{ NR } & 0 & 0 & 7.58 & --- & 750 \\
\hline & 8.13 & 10 & 8.3 & 13.47 & 770 \\
\hline & 15.04 & 20 & 13.37 & 11.73 & 825 \\
\hline & 26.14 & 40 & 9.17 & 4.63 & 780 \\
\hline & 34.68 & 60 & 8.98 & 3.42 & 780 \\
\hline \multirow{5}{*}{ NBR } & 0 & 0 & 5.87 & --- & 500 \\
\hline & 8.13 & 10 & 7.4 & 15.51 & 520 \\
\hline & 15.04 & 20 & 9.3 & 10.54 & 540 \\
\hline & 26.14 & 40 & 11.4 & 7.43 & 570 \\
\hline & 34.68 & 60 & 10.4 & 5.11 & 550 \\
\hline
\end{tabular}

${ }^{a}$ Tensile strength

${ }^{\mathrm{b}}$ Elongation at break, \%

The reinforcing index (RI) shown in Table (4) is an empirical parameter representing reinforcement effect on a mechanical property [9], and defined as:

$$
\mathrm{RI}=\left(\frac{\mathrm{N}}{\mathrm{N}_{\mathrm{o}}}\right)\left(\frac{\mathrm{CaCO} \text { Content } \%}{100}\right)
$$

where $\mathrm{N}$ and $\mathrm{N}_{\mathrm{o}}$ are nominal values obtained by mechanical measurements of the specimen with and without $\mathrm{CaCO}_{3}$ respectively. 

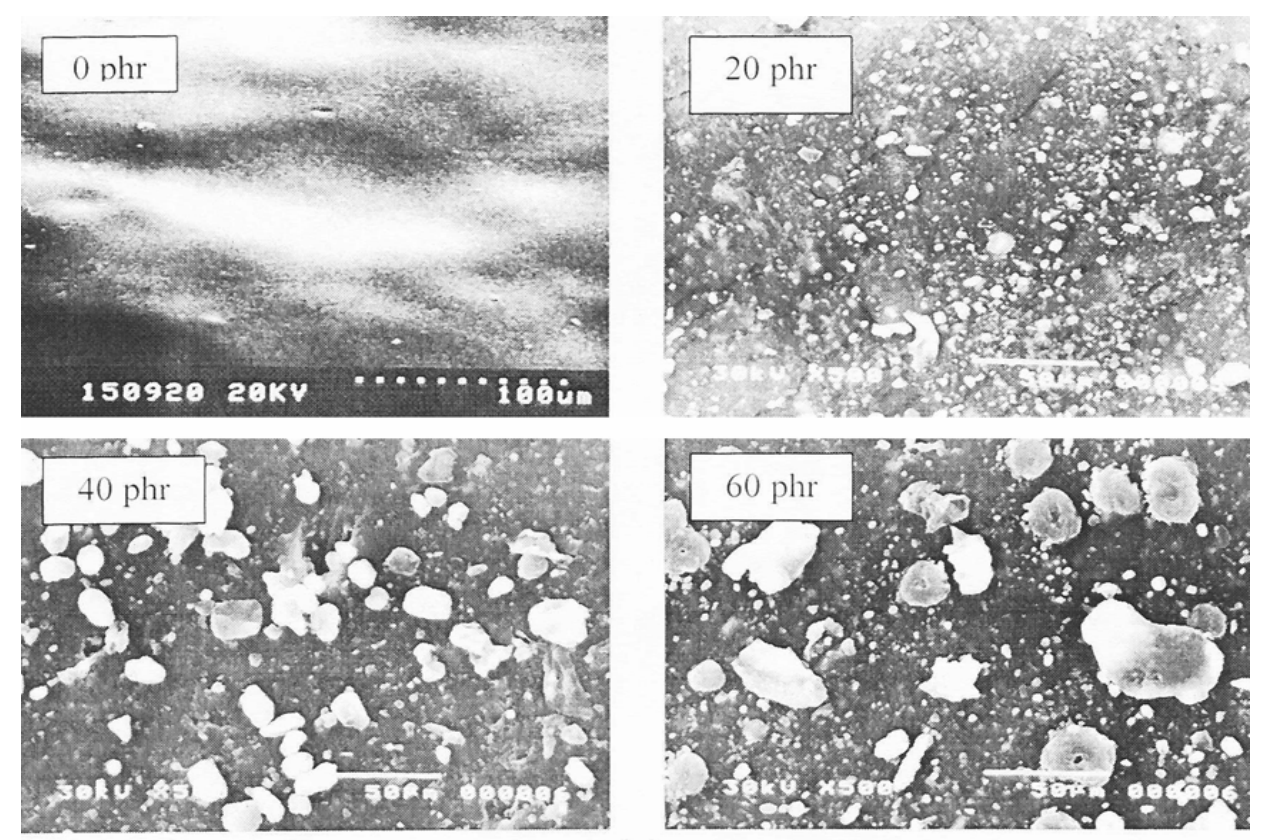

(a)
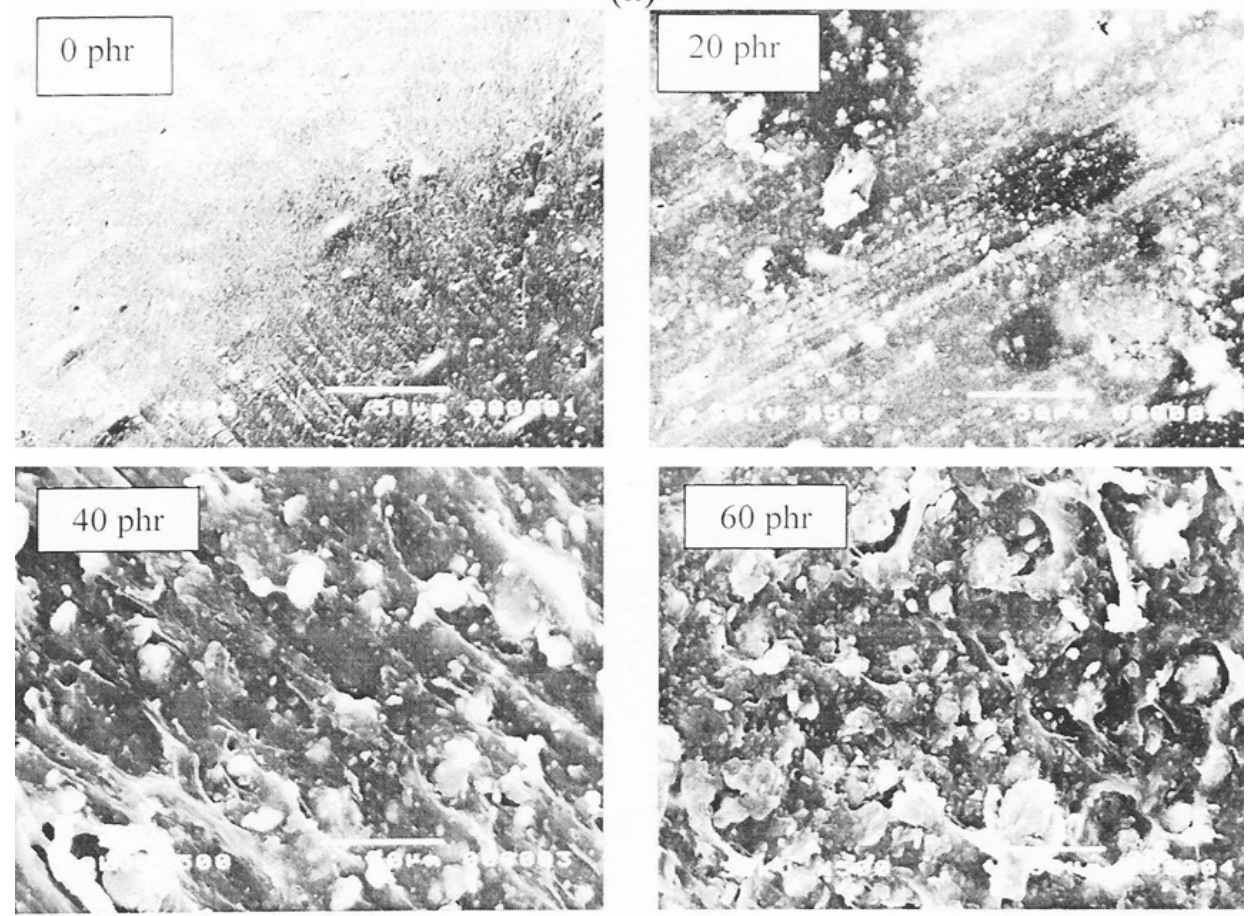

(b)

Fig. (4): SEM images of morphology of $\mathrm{CaCO} 3$ filled (a) NR, and (b) NBR vulcanizates. 


\subsubsection{Elongation at Break, $E_{b} \%$}

Table (4) exhibits also the influence of $\mathrm{CaCO}_{3}$ on the elongation at break, $\mathrm{E}_{\mathrm{b}} \%$, of the NR or NBR matrices. It is obvious that for the prepared rubber compounds, $\mathrm{E}_{\mathrm{b}} \%$ increases steadily, while it decreases gradually with increase in the filler loading. $\mathrm{CaCO}_{3}$ shows an extra extension due to the increase of the dilution effect that imparted at higher loading. For NBR matrix, $\mathrm{E}_{\mathrm{b}} \%$ exhibit lower values with $\mathrm{CaCO}_{3}$ increase, in comparison with NR matrix that are explained by the mutual reinforcement of the strain-induced crystallizable rubbers, which hinders the mobility of rubber chain molecules. On the other hand, the NBR matrix allows more rheological flow due to nearly good filler-rubber interaction and hence greater $\mathrm{E}_{\mathrm{b}} \%$ is obtained in this matrix, i.e. good toughening material.

\subsection{Electron Microscope Measurements}

The morphologies of NR and NBR compounds that filled with different concentrations of $\mathrm{CaCO}_{3}$ are shown in Fig. (4). Images of morphologies of NR matrix, Fig. (4a) show finer dispersion at $20 \mathrm{phr}$, while aggregates are visible at higher loading. For the NBR matrix, Fig. (4b), the critical dispersion appeared difficult to obtain where small particles are too high for sufficient dispersion at $40 \mathrm{phr}$.

\subsection{Effect of Aging Behavior on the Physicomechanical Properties}

The prepared samples were subjected to different $\gamma$-irradiation doses to estimate their aging behavior. The retained values of stress at rupture, elongation at rupture and equilibrium swelling in toluene were determined after aging and are given in Figures (5, 6 and 7). These physicomechanical properties show the dependence of both stress and strain at rupture, and equilibrium swelling on the aging dose up to $50 \mathrm{Mrad}$. It is also noticed that the increase of $\mathrm{CaCO}_{3}$ concentration increases the retained values up to $20 \mathrm{phr}$ and $40 \mathrm{phr}$ for NR and NBR respectively. Therefore, the use of $\mathrm{CaCO}_{3}$ as reinforcement filler improves the physicomechanical properties of the aging resistance to $\gamma$ irradiation. While at higher concentrations for each, a degradation process of rubber chains is more predominant than crosslinking. 

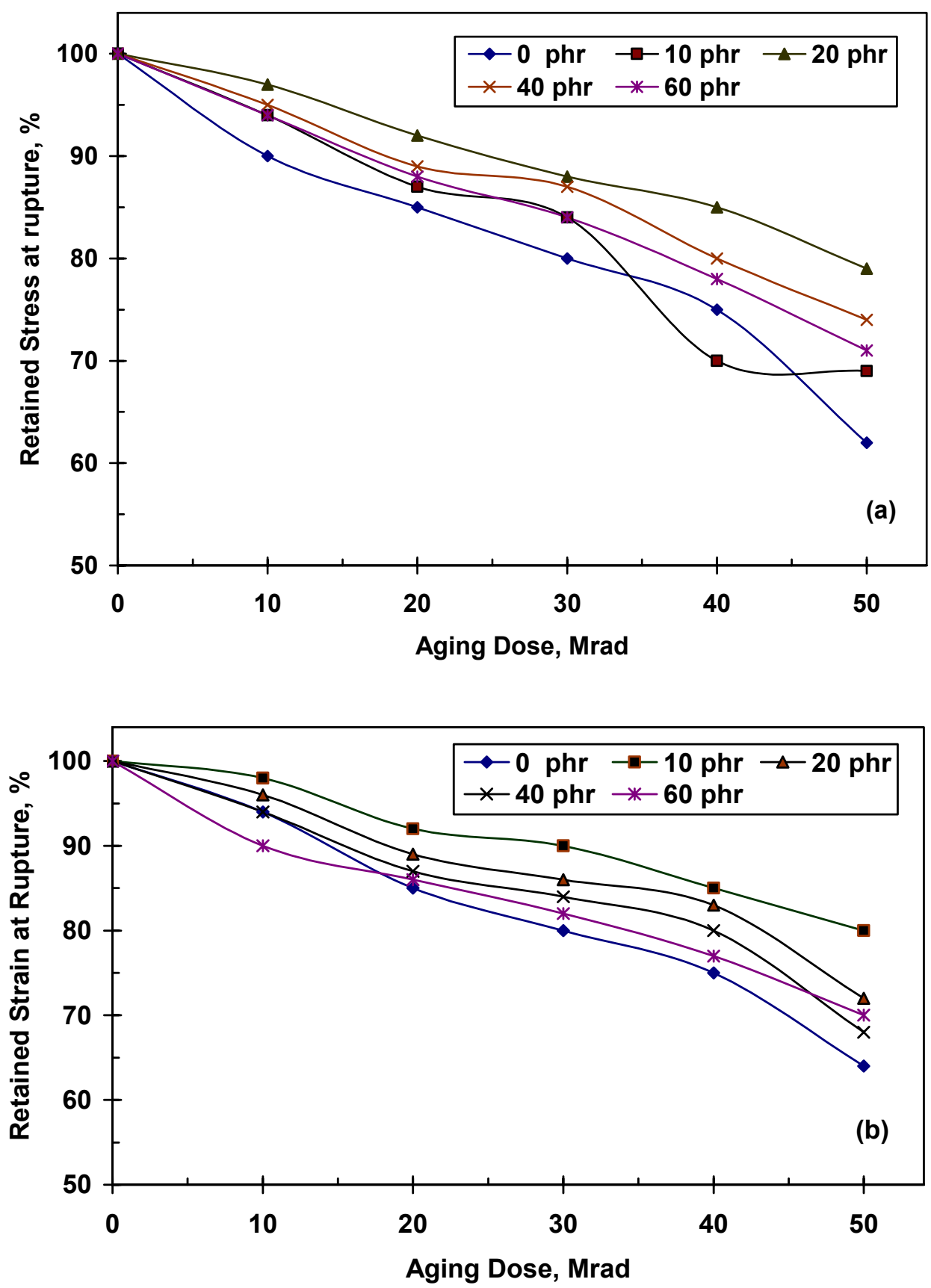

Fig. (5): Retained (a) stress at rupture, \%, and (b) strain at rupture, \%, as a function of the $\gamma$-irradiation dose for NR vulcanizates at different concentration of $\mathrm{CaCO}_{3}$. 

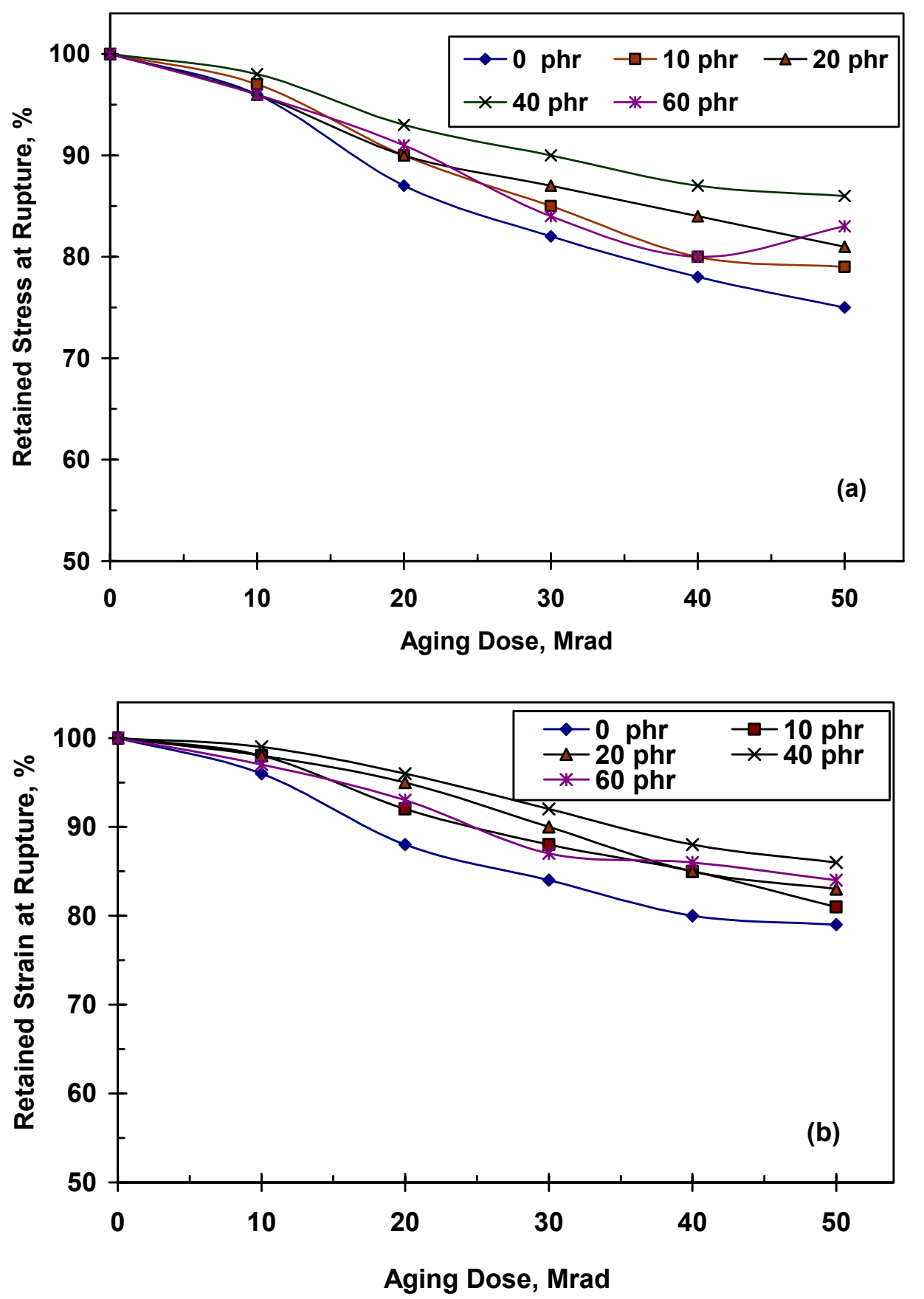

Fig. (6): Retained (a) stress at rupture, $\%$, and (b) strain at rupture, $\%$, as a function of the $\gamma$-irradiation dose for NBR vulcanizates at different concentration of $\mathrm{CaCO}_{3}$. 

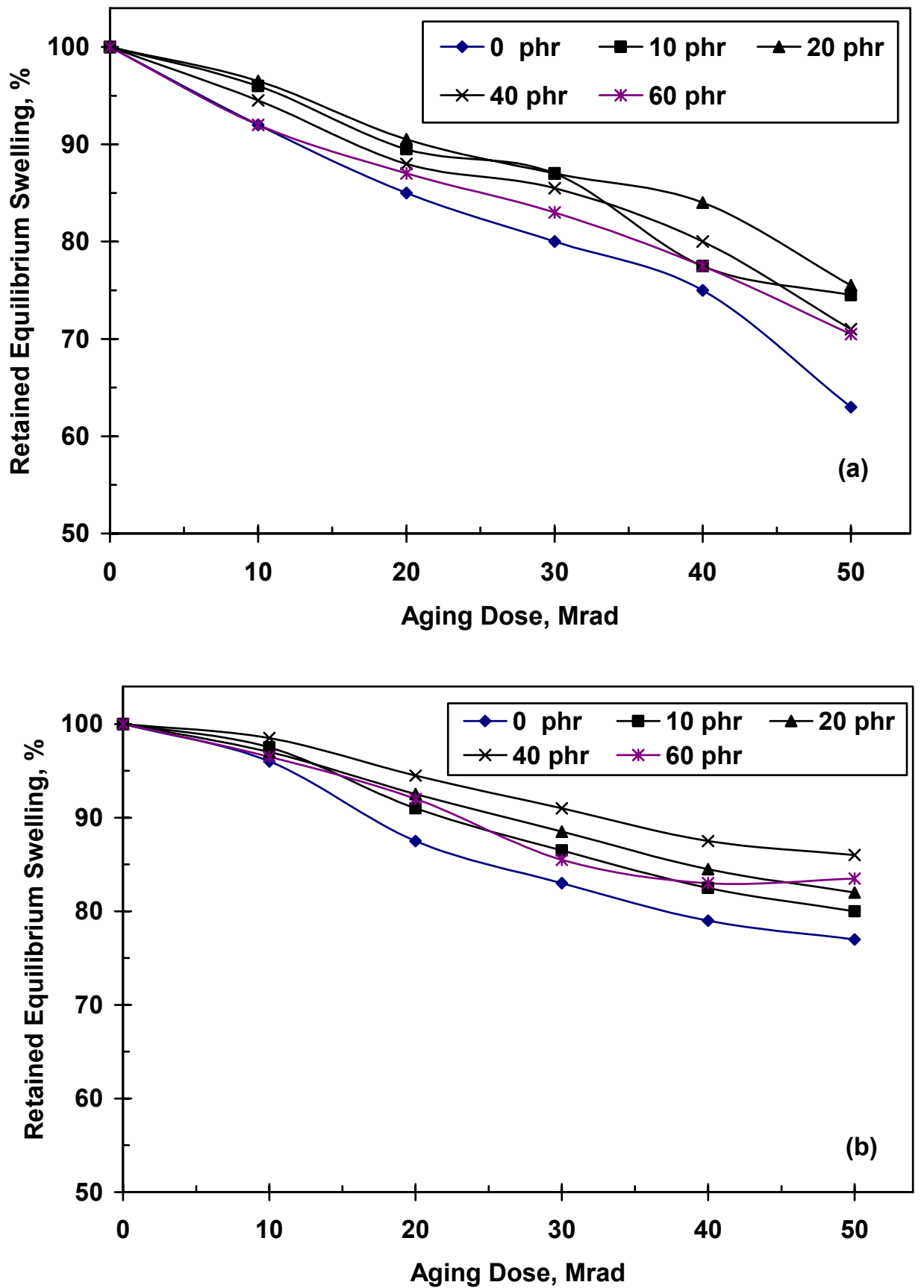

Fig. (7): Retained equilibrium swelling, \%, of (a) NR, and (b) NBR, as a function of the $\gamma$-irradiation dose at different concentration of $\mathrm{CaCO}_{3}$. 


\section{Conclusions}

- The cure characteristics and the physicomechanical properties of $\mathrm{CaCO}_{3}$ reinforcement NR or NBR compounds depend mainly on both the filler concentration and the type of the used rubber.

- The optimum concentrations of $\mathrm{CaCO}_{3}$ are $20 \mathrm{phr}$ and $40 \mathrm{phr}$ for NR and NBR respectively. While at higher filler contents, all the measured properties are decreased, resulting in a poor dispersion of the filler on the rubber matrix, filler agglomeration.

- The use of $\mathrm{CaCO}_{3}$ as reinforcement filler improves the physicomechanical properties of the aging resistance to $\gamma$-irradiation. While at higher concentrations for each, a degradation process of rubber chains is more predominant than crosslinking.

\section{References:}

1. G. Kraus, Ed., "Reinforcement of Elastomers," Interscience, New York, 1965.

2. C.M. Blow, "Rubber Technology and Manufacture," Buterworth, London, 1971.

3. M.P. Wagner, in "Rubber Technology," M. Morton, Ed., Reinhold, New York, 1987.

4. H. Ishida, "Interfacial Phenomena in Polymer, Ceramic and Metal Matrix Composites," Elsevier, New York, 1988.

5. A.I. Medalia and G. Kraus, in "Science and Technology of Rubber," $2^{\text {nd }}$ ed., J.E. Mark, B.Erman, and F.R. Eirich, Eds., Academic Press, San Diego, 1994.

6. S. Wolff and M-J. Wang, Rubber chem. Technol. 65, 329 (1992).

7. S. Wolff, Rubber Chem. Technol. 69, 325 (1996).

8. G.R. Hamed, Rubber Chem. Technol. 73, 524 (2000).

9. S. Kohjiya and Y. Ikeda, Rubber Chem. Technol. 73, 534 (2000).

10. B.T. Poh, C.P. Kwok and G.H. Lim, Eur. Polym. J. 31. 223 (1995).

11. B.T. Poh, H. Ismail and K.S. Tan, Polym. Testing 21, 801 (2002).

12. A.L.N. da Silva, M.C.G. Rocha, M.A.R. Moraes, C.A.R. Valente, and F.M.B. Coutinho, Polym. Testing 21, 57 (2002).

13. W.C.J. Zuiderduim, C. Westzaan, J. Huetink, and R.J. Gaymans, Polymer 44, 261 (2003).

14. L.A. Wells, P.E. Cassidy, T.M.A. Aminabhavi, and R.B Perry, Rubber Chem. Technol. 63, 66 (1990).

15. Y. H. Bae, T. Okano, and S. W. Kim; J. Polym. Sci.: Polym. Phys., 28, 923 (1990).

16. M. S. Sobhy, M. M. Mahdy, M. A. K. El-Fayoumi and E. M. Abdel-Bary, Polym. Testing, 16, 349 (1997). 
17. J. Flory and J. Rhener, J. Chem. Phys. 11, 512 (1943).

18. R.S. Rivlin, Rubber Chem. Technol. 65 , G 51 (1992).

19. J.H. Hildebrand and R.L. Scott, "The Solubility of non-electrolyte", $3^{\text {rd }}$ Ed., New York: Van Nostrand Reinhold; 1950.

20. B.T. Poh, H. Ismail, E.H. Quah and P.L. Chin, J. Appl. Polym. Sci. 81, 47 (2001).

21. A.S. Aprem, S. Jose, S. Thomas, N.M. Barkoula and J.K. Kocsis, Eur. Polym. J. 39, 69 (2003). 